\title{
Skala Peminatan: Instrumen Alternatif Identifikasi Kecenderungan Minat
}

\author{
Eko Susanto, M.Pd.,Kons. \\ ekobkummetro@gmail.com \\ HP : +62813 69149853 \\ Universitas Muhammadiyah Metro \\ Yuni Novitasari, M.Pd. \\ yunibkumm@gmail.com \\ HP : +6282121984590 \\ Universitas Muhammadiyah Metro
}

\begin{abstract}
ABSTRAK
Tuntutan kurikulum 2013 harus segera dipenuhi oleh Guru BK/Konselor di sekolah. Terkait dengan peminatan Guru BK/Konselor diharapkan mampu mengidentifikasi dan membuat rekomendasi arah peminatan peserta didik. Rekomendasi dari Guru BK/Konselor di SMP/MTs menjadi salah satu referensi penempatan peminatan yang sesuai bagi Guru BK/Konselor di SMA/MA/SMK/MAK. Melihat kenyataan dilapangan tidak semua sekolah mampu menyelenggarakan tes psikologi maka, artikel ini menyajikan model Skala Peminatan sebagai instrumen alternatif identifikasi kecenderungan minat. Skala ini dimodifikasi dari angket penelusuran minat dengan perubahan pada beberapa bagian. Terdiri dari 126 butir item dan 14 aspek arah peminatan SMA dan SMK, dengan tipe jawaban skala model Likert 0 s.d. 4. Skala Peminatan juga dilengkapi dengan Analisis Skala Peminatan (ASP) yaitu aplikasi komputer untuk mempermudah proses analisis data. Aplikasi didesain user friendly agar mudah diaplikasikan dan tidak perlu waktu lama untuk mempelajarinya. Hasil analisisnya berupa profil kelompok, grafik dan profil individu berupa lembar rekomendasi arah peminatan. Skala ini juga dapat dipadukan dengan data instrumen asesmen lainnya baik tes maupun non tes. Semoga bermanfaat.
\end{abstract}

Kata kunci : guru_bk, konselor, rekomendasi, skala, peminatan, aplikasi_komputer 


\section{PENDAHULUAN}

Perubahan kurikulum pada satuan pendidikan dasar dan menengah disadari atau tidak telah memberi dampak pada lingkungan kerja Guru BK/Konselor. Penyempurnaan kurikulum KTSP ke kurikulum 2013 sebagai upaya menuju kemajuan yang berbanding lurus dengan konsekuensi pengiringnya. Kurikulum 2013 sebagai penyempurnaan kurikulum sebelumnya, berfokus pada proses pendidikan yang memberi kesempatan lebih pada peserta didik untuk mengembangkan kemampuan dan minatnya (Mamat Supriatna, 2013). Kualitas pendidikan sangat mungkin berawal dari sebuah perencanaan yang baik dan kinerja pelaksanaan yang baik pula. Peminatan menjadi bagian topik pembahasan dalam kurikulum 2013, guru $\mathrm{BK} /$ konselor disekolah diberi tanggung jawab sebagai pelaksana program peminatan tersebut.

Terkait dengan peminatan guru BK/ konselor diharapkan mampu mengidentifikasi minat sejak dini dan membantu mengarahkan minat yang sesuai dengan diri peserta didik. Rekomendasi dari Guru BK/Konselor di SMP/MTs menjadi salah satu bahan referensi bagi Guru BK/Konselor di SMA/MA/SMK/ MAK pada penempatan peminatan yang sesuai. Identifikasi arah peminatan peserta didik dapat dilakukan dengan pendekatan tes dan non tes. Pendekatan tes biasanya dilakukan denan menggunakan instrumen baku seperti alat tes psikologi yang kita kenal. Sedangkan pendekatan non tes dilakukan berdasarkan datadata dari instrumen tak baku, misalnya presgtasi akademik, observasi, wawancara, angket dsb.

Masalah yang muncul dilapangan saat ini adalah belum semua SMP/MTs mampu menyelenggarakan tes baku dengan beragam alasan. Diantara alasannya adalah alasan finansial, tes baku dipandang membutuhkan pendanaan yang tidak sedikit. Kemudian alasan profesional, masih ada yang merasa belum mampu menyelenggarakan peminatan. Berawal dari masalah itu penulis berinisiatif untuk mencoba mengembangkan instrumen alternatif identifikasi kecenderungan minat. Pada artikel ini penulis akan membahas instrumen yang telah dikembangkan.

Tujuan pengembangan ini dilakukan untuk membantu guru BK/konselor disekolah, terkait dengan kegiatan asesmen arah peminatan peserta didik. Sejatinya instrumen ini dikembangkan untuk SMP/MTs, dalam aplikasinya juga dapat digunakan oleh guru BK/konselor di SMA/MA/SMK/ MAK. Dengan begitu guru BK/konselor dapat mengidentifikasi kecenderungan minat siswa sejak dini dan sesuai dengan kebutuhannya.

\section{METODE PENELITIAN}

Penelitian dilakukan dengan pendekatan kuantitatif yang dilakukan dalam empat tahap, sbb: 1) analisis kebutuhan, 2) pengembangan prototipe, 3) ujicoba pengguna, 4) analisis psikometrik. Tahap analisis kebutuhan merupakan usaha yang dilakukan untuk mengetahui tingkat kebutuhan pada skala peminatan yang sedang dikembangkan, sekaligus mengetahui masalah yang terjadi dilapangan. Tahap pengembangan prototipe adalah kegiatan menulis pernyataan sakala peminatan dengan memperhatikan aspek bahasa, konsep teoretik , kesesuaian dengan perkembangan target responden dan validasi ahli. Tahap ujicoba pengguna adalah kegiatan ujicoba prototipe skala peminatan kepada pengguna, seleksi item, dan revisi. Tahap analisis psikometrik adalah kegiatan analisis validitas dan reliabilitas item, serta penyusunan skala peminatan. Langkah pengembangan ini mengadaptasi langkah pengembangan milik Azwar (2013).

\section{HASIL DAN PEMBAHASAN}

Penelitian yang dilakukan masih dalam proses penyelesaian. Hasil sementara dijelaskan sebagai berikut:

1. Konsep dan konstruk; skala peminatan dikembangakna mengacu pada definisi minat menurut Crow dan Crow (dalam Djaali, 2007), Doyles Fryer (dalam Nurkencana, 1993), dan Sukardi (1994). Minat merupakan gejala psikis atau dorongan pada diri seseorang dalam melakukan tindakan yang didasari oleh perasaan senang-tidak senang atau sukatidak suka terhadap suatu objek tertentu. Objek yang dimaksudkan disini bisa orang, benda, kegiatan, dan pengalaman. Dari pendapat tersebut kemudian dikembangkan aspek-aspek minat yang akan diukur. Karena skala peminatan ini diarahkan khusus pada program peminatan disekolah maka dibuatlah 14 aspek peminatan di SMA/MA dan SMK/MAK sesuai dengan 
peminatan yang dimaksudkan pada kurikulum 2013. Dari setiap aspek jabarkan kedalam 9 butir item pernyataan kegiatan. Secara keseluruhan terdapat 126 butir item, yang disajikan dengan tipe jawaban skala model Likert, dengan penskalaan 0 s.d. 4. Butir item diadaptasi dari beberapa instrumen yang sudah ada sebelumnya yakni instrumen penelusuran minat milik Dr. Mamat Supriatna, M.Pd., Dr. Nandang Budiman, M.Si., Hadi Pranoto, S.Pd., dan Hanik Mukaromah, S.Psi.

2. Skala peminatan yang disempurnakan melewati proses revisi dan reviu pada bagian-bagian tertentu, dijelaskan sebagai berikut:

3. Aspek Instrumen; tetap mengacu instrumen asli yang terdiri dari 14 aspek yang akan diukur, diberi kode sama dengan yang asli hanya sedikit revisi deskripsi, sebagai berikut:

\begin{tabular}{|l|l|l|}
\hline Kode & Deskripsi asli & Deskripsi revisi \\
\hline A & Keagamaan & Keagamaan \\
\hline B & Matematika & Matematika \\
\hline C & IPA & IPA \\
\hline D & IPS & IPS \\
\hline E & Bahasa dan budaya & Bahasa dan budaya \\
\hline F & Teknologi dan & Teknologi dan rekayasa \\
\hline G & $\begin{array}{l}\text { Teknologi dan ilmu } \\
\text { komunikasi }\end{array}$ & $\begin{array}{l}\text { Teknologi informasi } \\
\text { dan komunikasi }\end{array}$ \\
\hline H & Kesehatan & Kesehatan \\
\hline I & $\begin{array}{l}\text { Agro bisnis dan agro } \\
\text { teknologi }\end{array}$ & $\begin{array}{l}\text { Agribisnis dan } \\
\text { agroteknologi }\end{array}$ \\
\hline J & $\begin{array}{l}\text { Perikanan dan } \\
\text { kelautan }\end{array}$ & Perikanan dan kelautan \\
\hline K & $\begin{array}{l}\text { Bisnis dan } \\
\text { manajemen }\end{array}$ & Bisnis dan manajemen \\
\hline L & Pariwisata & Pariwisata \\
\hline M & Seni dan kerajinan & $\begin{array}{l}\text { Seni pertunjukkan dan } \\
\text { kerajinan }\end{array}$ \\
\hline N & Keolahragaan & Keolahragaan \\
\hline
\end{tabular}

Perubahan dilakukan atas dasar kesesuaian istilah yang ada pada struktur kurikulum. Hal ini dilakukan hanya untuk mempermudah memahami istilah yang nantinya akan digunakan pada peminatan disekolah.

4. Proporsi item pernyataan; item pernyataan sebagian masih menggunakan pernyataan dari instrumen asli dan sebagian saya tambahkan. Jumlah pernyataan awalnya tidak seimbang, saya menambahkan dan mengurangi pada beberapa bagian sehingga proporsinya seimbang. Hal ini dilakukan hanya untuk mempermudah skoring. Berikut penjelasannya jumlah item asli dan revisi:

\begin{tabular}{|l|l|l|l|}
\hline Kode & \multicolumn{1}{|c|}{ Deskripsi revisi } & $\begin{array}{c}\text { Jumlah } \\
\text { item } \\
\text { asli }\end{array}$ & $\begin{array}{c}\text { Jumlah } \\
\text { item } \\
\text { revisi }\end{array}$ \\
\hline A & Keagamaan & 9 & 9 \\
\hline B & Matematika & 8 & 9 \\
\hline C & IPA & 9 & 9 \\
\hline D & IPS & 6 & 9 \\
\hline E & Bahasa dan budaya & 8 & 9 \\
\hline F & Teknologi dan rekayasa & 9 & 9 \\
\hline G & $\begin{array}{l}\text { Teknologi informasi dan } \\
\text { komunikasi }\end{array}$ & 6 & 9 \\
\hline H & Kesehatan & 7 & 9 \\
\hline I & $\begin{array}{l}\text { Agribisnis dan } \\
\text { agroteknologi }\end{array}$ & 10 & 9 \\
\hline J & Perikanan dan kelautan & 9 & 9 \\
\hline K & Bisnis dan manajemen & 9 & 9 \\
\hline L & Pariwisata & 8 & 9 \\
\hline M & $\begin{array}{l}\text { Seni pertunjukkan dan } \\
\text { kerajinan }\end{array}$ & 7 & 9 \\
\hline N & Keolahragaan & 5 & 9 \\
\hline
\end{tabular}

5. Tipe jawaban, instrumen yang asli menggunakan tipe jawaban "YA" dan "TIDAK". Kemudian dirubah dengan tipe jawaban skala model Likert menjadi sebagai berikut:
a. Suka Sekali (SS)
$=4$
b. Suka (S)
$=3$
c. Biasa Saja (BS)
$=2$
d. Kurang Suka (KS)
$=1$
e. Tidak Suka (TS)
$=0$

Menurut Azwar (2013), tipe jawabanmodel likert memiliki bentuk respon jawaban yang lebih berdimensi. Senada dengan itu berdasarkan laporan penelitian yang dilakukan Setiawati (2012) menyatakan penggunaan tipe jawaban model skala Likert memiliki reliabilitas yang lebih tinggi dibandingkan dengan tipe jawaban Ya dan Tidak.

6. Buku Manual: Instrumen yang asli belum menyediakan buku manual, pada instrumen yang direvisi dilengkapi dengan buku manual yang berisi tentang informasi skala peminatan, petunjuk penyajian, dan tutorial. Buku manual ini sekaligus sebagai sebagai panduan bagi Guru BK/Konselor disekolah, agar lebih memahami hakikat dari pengukuran yang dilakukan menggunakan skala peminatan. 
7. Aplikasi: revisi juga dilakukan pada aplikasi program komputer. Aplikasi yang asli masih sangat sederhana belum begitu kompleks dan tidak menyediakan profil individual. Revisi menghasilkan tampilan profil yang lebih lengkap dan memiliki lembar rekomendasi arah peminatan yang diolah secara otomatis.

8. Susunan item pernyataan; susunan item yang asli, pernyataan dikelompokkan dalam satu aspek dan diberi nomor secara berurutan. Perubahan dilakukan dengan membuat kelompok pernyataan yang dibuat acak, setiap kelompok butir item diwakili setiap aspek peminatan. Sehingga pernyataan pada setiap aspek akan diberi nomor tidak berurutan. Berikut contoh perubahannya:

\begin{tabular}{|l|l|l|l|}
\hline \multicolumn{2}{|c|}{ Susunan Asli } & \multicolumn{2}{c|}{ Susunan Revisi } \\
\hline A1 & $\begin{array}{l}\text { Suka mempelajari kisah } \\
\text { teladan tokoh agama }\end{array}$ & A1 & $\begin{array}{l}\text { Mempelajari kisah } \\
\text { teladan tokoh agama }\end{array}$ \\
\hline A2 & $\begin{array}{l}\text { Suka mendengarkan } \\
\text { lagu-lagu religi }\end{array}$ & B1 & $\begin{array}{l}\text { Menjadi ahli } \\
\text { matematika }\end{array}$ \\
\hline A3 & $\begin{array}{l}\text { Suka mempelajari kitab } \\
\text { suci }\end{array}$ & C1 & $\begin{array}{l}\text { Mengamati kejadian } \\
\text { alam }\end{array}$ \\
\hline A4 & $\begin{array}{l}\text { Suka mengisi waktu } \\
\text { luang dengan membaca } \\
\text { buku keagamaan }\end{array}$ & D1 & $\begin{array}{l}\text { Mempelajari peta } \\
\text { dan permukaan bumi }\end{array}$ \\
\hline A5 & $\begin{array}{l}\text { Tertarik untuk } \\
\text { menyimak ceramah } \\
\text { agama }\end{array}$ & E1 & Mendengarkan cerita \\
\hline A6 & $\begin{array}{l}\text { Suka mempelajari do'a- } \\
\text { do'a }\end{array}$ & F1 & $\begin{array}{l}\text { Menggambar } \\
\text { bangunan }\end{array}$ \\
\hline A7 & $\begin{array}{l}\text { Suka mendalami makna } \\
\text { ibadah }\end{array}$ & G1 & $\begin{array}{l}\text { Membuat desain } \\
\text { grafis website }\end{array}$ \\
\hline A8 & $\begin{array}{l}\text { Suka mengikuti kegiatan } \\
\text { di tempat ibadah }\end{array}$ & H1 & $\begin{array}{l}\text { Melakukan kegiatan } \\
\text { P3K }\end{array}$ \\
\hline A9 & $\begin{array}{l}\text { Suka menyampaikan } \\
\text { pesan-pesan keagamaan }\end{array}$ & I1 & $\begin{array}{l}\text { Mempelajari teknik } \\
\text { bercocok tanam }\end{array}$ \\
\hline
\end{tabular}

Perubahan dilakukan untuk menghindari terjadinya facking yang menjadi sebab terjadinya bias pengukuran. Perubahan ini juga dilakukan agar siswa tidak mudah menebak aspek yang akan diukur dari suatu kelompok pernyataan. Jika siswa tahu bahwa item dengan kode A akan mengukur minat tertentu maka siswa akan memberi jawaban yang palsu.

9. Lembar jawaban; dengan tipe jawaban yang berubah maka lembar jawaban pun disesuaikan dengan tipe jawaban. Pada sisi kanan lembar jawaban juga saya sertakan kolom untuk skoring manual. Berikut gambaran perubahannya.

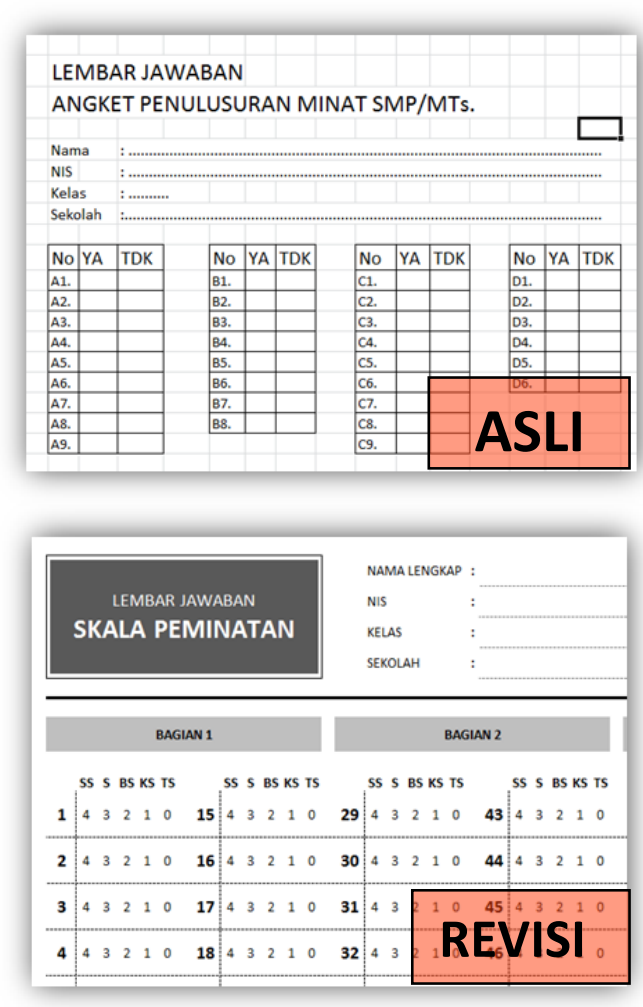

10. Ujicoba Instrumen; ujicoba instrumen dilakukan pada siswa SMP Negeri 2 Metro, dengan jumlah responden sebanyak 82 siswa. Dari data yang diperoleh kemudian dilanjutkan dengan analisis koefisien korelasi item total untuk mengetahui validitas butir item dan analisis koefisien konsistensi internal untuk mengetahui tingkat kepercayaan butir item pada pengukuran. Hasil analisis validitas item dari 126 butir item terseleksi 9 butir item yang memiliki Corrected ItemTotal Correlation dibawah 0,250 hal ini menunjukkan butir item memiliki validitas item yang rendah (Azwar, 2013), maka tersisa 117 item yang memiliki validitas tinggi. Hasil analisis reliabilitas dari 126 butir item diperoleh koefisien alpha sebesar 0,969 setelah item diseleksi menjadi 117 item diperoleh koefisien reliabilitas 0,970. Dengan koefisien konsitensi $\geq 0,950$ maka skala peminatan ini dapat digunakan sebagai dasar pengambilan keputusan individual untuk merekomendasikan arah peminatan siswa (Azwar, 2013). 


\section{PENUTUP}

Kesimpulan; Skala Peminatan sampai saat ini sudah dapat digunakan untuk membantu mengindentifikasi arah peminatan siswa di SMP/MTs. Skala peminatan ini juga dapat digunakan di SMA/MA/SMK/MAK untuk tujuan yang sama. Jika digunakan di SMP/MTs rekomendasinya bisa digunakan oleh wali kelas dan guru $\mathrm{BK} /$ konselor untuk membantu mengarahkan minat siswa sejak dini. Sehingga ketika siswa masuk di SMA/MA/SMK/MAK mereka berada pada peminatan yang sesuai.

Saran; Dalam menggunakan hasil skala peminatan ini sangat direkomendasikan untuk dipadukan dengan hasil asesmen lain, misalnya hasil belajar, harapan orang tua, dan lain sebagainya. Keputusan yang diambil akan lebih baik kualitasnya jika didasarkan pada data yang komprehensif. Demikian sedikit kontribusi yang dapat penulis lakukan untuk kemajuan Bimbingan dan Konseling ke depan. Semoga Bermanfaat.

\section{DAFTAR RUJUKAN}

Azwar, Saifuddin. 2013. Penyusunan Skala Psikologi (Edisi 2). Yogyakarta: Pustaka Pelajar

Djaali, H. 2007. Psikologi Pendidikan. Jakarta: Bumi Aksara

Sukardi, Dewa Ketut. 1994. Tes Dalam Konseling Karir. Surabaya: Usaha Nasional

Nurkancana, W. \& Sumartana, P. 1986. Evaluasi Pendidikan. Surabaya: Usaha Nasional

Farida Agus Setiawati. 2012. Penskalaan Multiple Intelligences Sebagai Salah satu Alternatif Instrumen untuk Mengukur Karakter Bangsa yang Cerdas. Artikel disajikan pada Konferensi HEPI di Unesa.

Hadi Pranoto. 2011. Tes Minat. Diakses 5 Agustus 2013, dari http://hadipranoto.guruindonesia.net/artikel detail-41338.html 